\title{
浅谈风景园林设计的植物配置与规划
}

李婷

滕州市园林管理处

DOI:10.18686/bd.v2i2.1221

[摘 要] 在现代园林建设过程中,植物配置应根据施工现场的实际情况和功能要求,结合植物本身的生态习性,进一步提高 园林绿化的整体效果, 为人们提供一个更舒适的生活环境。本文讨论了景观设计的植物配置和规划。

[关键词] 风景园林; 植物; 配置; 养护

\section{1 园林植物配置的基本要素}

1.1 植物配置的内涵

园林植物不仅可以改善居住环境, 为休闲文化活动提 供场所,还可以为人们造访和观赏创造艺术空间。顾名思义, 植物配置是利用树木, 灌木,藤条和草药景观创造出来的,充 分发挥自然的身体形态,线条,色彩等自然美景,以完美的植 物景观种植。设计的科学性和艺术性必须高度统一。也就是 说, 它不仅满足了植物与环境的统一, 对生态适应性的要求, 而且通过艺术构成的原则, 体现了植物和群体的形式美,美 国产生了美。植物景观中的艺术创作非常细淢和复杂。诗意 的体现体现了绘画艺术的原则和古典文学的运用, 巧妙地 利用植物的形态,线条,色彩和纹理进行构图,并经过植物的 阶段和生命周期的变化,它是一个活跃的动态构成。

1.2 植物配置的基本要素

园林植物配置是景观规划设计的重要组成部分。按照 植物生态习性和景观布局要求, 合理配置园内各种植物,发 挥其园林特色和观赏特色。植物在一年四季的生长过程中, 叶,花,果的形状和颜色随季节而变化,当开花时,结果或者当 变色时,具有很高的观赏价值, 园林植物的分配要充分利用 植物季节相特征。在不同的气候带, 不同的气候带植物的季 节性表现不同,即使在同一地区,气候正常与否,往往会影响 色彩的季节性外观, 低温和干旱会延缓种子的萌发和开花, 例如红叶的一般需求当昼夜温差变红时, 如果霜过早出现, 叶先不变红, 不能产生美丽的秋季。土壤, 养护管理等因素也 影响季节变化,因此季节变化可以手动控制。

\section{2 园林植物配置的原则}

2.1 符合本地条件

在进行园林植物的配置时, 要考虑当地的气候和土壤 的特点。气候要首先考虑, 因为其直接对植物的生存产生影 响, 从而影响需要配置的植物; 不同的植物所需要的土壤环 境有所不同, 比如, 北方多为中性偏碱性的土壤, 适合榆叶 梅、枸杞等植物的生长。

2.2 符合生态要求

环境中所有的生态因子, 对于植物的生存有着很大的 影响, 不同植物种类的搭配直接影响到树木花卉的成活与 否。

\section{3 符合艺术要求}

园林植物的配置, 与植树造林不同, 要考虑到每种植物 的色彩、形态、芳香、风韵等美的特色,兼顾到形式与内容的 统一, 从而达到情景交融的艺术效果。

\section{3 配置过程中相关的注意事项}

3.1 合理配置植物,尽量避免出现随意性。在配置上,应 该考虑当地的发展要求,历史, 建筑和文化。只有通过建设文 化背景, 发展要求和周边建筑的协调, 才能真正达到合理科 学的目的。同时要充分考虑施工现场自身功能的要求, 及时 了解和掌握工厂的生态习惯, 结合施工现场的环境条件和 气象条件,合理科学安排工厂。以避免植物配置中的盲目性 和可选性。突出地方风貌文化特色, 全面提升园林绿化产 品。

3.2 加强乡土树种优势的发挥。在现代园林景观中,使 用本土植物是非常重要的。本地物种是指该地区在这种特 殊情况下的所有树种。这种树种具有较好的经济性,适应性, 珍贵性, 多样性, 观赏性和抗性, 比其他物种适应气候条件和 土壤条件。为确保植物生态,生理生化等功能能正常运行, 进 一步使其装饰得到充分论证。

3.3 在配置植物时,应首先使用绿色植物作为其配置的 基础。植物应根据自己的生长习性和不同季节的变化配置 植物, 并配置成藤组合, 成为一个多层次的植物群落。根据植 物群落生长规律, 合理, 科学地实施人工控制。为了有效地保 护景观植物, 可以在公园内开辟践踏草坪, 以满足人们在绿 地各方面的需求。此外, 园林管理者还应加强病虫害管理, 尽 量减少使用除草剂,化肥,农药等一系列较为严重的化学成 分,以保护园林土壤的生态环境。

\section{4 风景园林设计中的植物配置方法}

4.1 生态环境保护是当代潮流的主题。景观建筑应该是 这一趋势的领导者之一。因此, 现代园林除了追求人的参与 外, 还追求自然的生态特性, 以满足人类回归自然的心理需 求。除了植物景观让人们享受, 更重要的是营造一个合适的 人类生态环境。园林绿化具有吸收二氧化碳, 释放氧气,降低 噪音, 节约土壤和水分, 净化空气, 调节温度, 湿度和风, 粉尘 等生态效应, 需要植物熟悉不同花园的生态习性和不同的 抗性植物在部署之前。科学, 选择植物种类, 最大限度地发挥 
不同植物的生态功能。

4.2 在园林植物中, 不同场合对植物的配置有不同的要 求。商业区内的植物高大优雅,慷慨大方, 不能遮掩商业门面 附近一些空间的立面。所以，你不能选择过于丰富的树木,而 应该是高大挺拔，树木精巧，叶子不是太富有的植物。对住宅 小区环境的要求较高,除绿化住宅绿化美化外,更重要的是 它为居民提供了日常户外休闲场合，植物配置应根据空间 环境和使用不同的配置原则。相对而言,社区植物布局层次 相对丰富,乔, 灌, 花, 草相结合, 打造出一个智能,生态, 健康的 休闲空间。水体是花园的重要组成部分,因为水花园,似乎灵 气,细淢。园内水体周围植物配置也很重要, 水宜种植具有防 潮, 不落叶的亲水植物, 水生植物, 还可以更适宜种植更多优 美的植物,如柳树,鸡脚齐,红枫等。

4.3 在园林的植物配置应该根据设计意图,景观设计概 念做不同的安排。如果一个园林的设计,景观建筑应该基于 程序分区的有效性,那么园林建筑的植物应该被区别对待。 如果正门与 “先抑后扬”或“直指点”的设计实践相比,工厂 配置有很大的不同。园林的植物配置也应该基于不同植物 的不同分区。儿童活动区的植物配置要求更加丰富多彩, 层 次要适宜,遮阳不宜过密,老年活动区需要配置更密集的植 物,创造一个安静的休闲空间。运动区植物配置应达到开放 的效果, 以适应运动的需要;文化娱乐区等各种建筑物都比 较密集,应该配置美化建筑物之间的对比,营造文化体育活 动和娱乐氛围。

4.4 园林中的植物配置还应注意季相变更观赏效果也 会跟着变更。植物是装饰美化环境的。因此,既要考虑不同 的植物在同一个季节在形态色彩上的不同，又要考虑到同 一种植物随着季节的不同所涌现的变更, 如树叶什么时候 变黄,什么时候开端落叶,什么时候开花, 什么时候成果等。 只有充分懂得了植物的季相变更,才干配置搭配好植物。风 景旅游区就更应器重植物的季相变更, 将植物在不同季节 的不同效果呈现给大家。

\section{5 园林植物配置中的树木养护}

园林树木的养护管理,在园艺建设中极其重要,人们常 说: “三分种,七分养”。这个养包括两个方面:一是养护,根据 树木不同的生长需要和特定要求,及时采取施肥、修剪、防 治病虫害、灌水、中耕除草等园艺技术措施; 二是管理,如绿 地的清扫保洁等园务管理工作等。除合理配置植物外,重要 的是要把园林树木与其他植物配置有机结合。因此应十分 重视园林树木的养护。

5.1 施肥

第一种方法是施肥基肥,在播种或播种前,将大量的化 肥犁埋在地下,一般有机肥; 第二次追肥,根据植物生长季节 和生长速度,所需肥料,一般用速效肥; 三是一种肥料, 播种 施肥,被誉为肥料种子, 种子细淢,成熟饱满,营养成分含量丰
富,如堆肥堆肥, 复合肥, 追肥, 在植物生长季节, 根据植物的 生长情况,及时喷酒植物,如喷施尿素溶液。

\section{2 修剪}

5.2.1 修剪绿筧。树筧定殖, 按规定的高度和形状, 及时 修剪, 以促进其枝叶生长最好的主梢最好切 $1 / 3$ 以上,切口 在指定高度 5 10cm 下面, 这样可以保证粗切口露出来, 最 后用平的绿篱修剪机,修剪树叶表面,注意树篱的表面(顶部 和两侧) 必须剪平, 修剪高度统一, 整齐统一, 击剑和墙体要 求光滑,棱角分明,及时修剪,保证在节日期间取出新枝叶,充 分发育,缺库存,及时补种,一年至少修剪两次。

5.2.2 修剪灌木丛。丛生的枝条应均衡生长,使内外植株 保持高低,自然丰满的球形。老枝子等老灌木过多定殖,应分 批规划疏枝,修枝新枝。然而,一些灌木(例如紫荆属)因为特 殊需要而栽培得高而干燥,所以在这里没有列出。在灌木丛 外部有规则的短截枝突起分枝,使灌木保持整齐平衡,但对 于一些带有拱形枝条的树木 (如连趐等),除长枝条发芽外。 留在植物上的剩余残留物应尽早切断, 以免食用营养物质。

5.2 .3 修剪落叶乔木。凡属具有中央领导干、主轴明显 的树种,应该尽量保持主轴芽的顶端,如果顶芽或主轴受损, 则应选择生长角生长中央分枝而不是垂直侧芽, 培养一个 新的主轴。主轴种类不明显,中心应选为较直枝的主导分枝, 尽快形成高大的树冠和丰满的冠冕, 不利于上述目的,如争 分枝,分枝,害虫等分支来控制打击。

\section{2 .4 防虫}

应注意植物多样性以提高植物免疫力。通过多种植物 的有机结合, 增加植物多样性, 利用物种间的相互制约,减少 病虫害的发生,从而形成稳定,有序, 抗逆的植物群落。另外, 合理化意味着要妥善布局,美化景观,还要科学利用植物之 间的关系, 配置有利于植物生长, 不利于种植结构病虫害的 发生和蔓延避免人为造成有利于病虫害的发生和传播的环 境条件。

\section{6 结束语}

总之,园林绿化是城市建设的重要组成部分,也是城市 文明的重要标志之一。如何使城市的景观美化得当, 关键是 如何配置景观植物。只要我们把握生态学的原理和美学原 理,掌握适当的方法,就一定能做好美化工作,让园林绿化成 为我们城市的一张新名片。

\section{参考文献:}

[1]夏小波.园林植物配置在园林绿化中的应用 [J]. 工 程建设与设计,2016,(10):5.

[2]张翔寅,梁娇. 浅议园林造景与植物配置 [J]. 现代园 艺,2017,(20):93.

[3]任苗娣.关于风景园林植物选择和配置方式的探究 [J].科技创新与应用,2016,(13):159. 